\title{
A study of body mass index in pregnancy and its correlation with maternal and perinatal outcome
}

\author{
Ramya S, Ashok Kumar, Shweta Sharan, Renuka Ramaiah \\ Correspondence: Dr Ramya S, Senior resident, Department of Obstetrics and Gynaecology, \\ ESICMC PGIMSR, Rajajinagar , Bengaluru, Karnataka, India; Email - \\ chaittra.shiv@gmail.com
}

Distributed under Attribution-NonCommercial-ShareAlike 4.0 International (CC BY-NC-SA 4.0)

\begin{abstract}
Objective: The aim of this study is to correlate the body mass index (BMI) in pregnancy with maternal and perinatal outcome. Method: The present study was conducted in 100 women attending antenatal outpatient department (OPD) from January 2015 to June 2016. The above women were placed in standard BMI categories and their obstetric and perinatal outcome variables were evaluated. Results: In this study we observed, increased rate of lower segment caesarian section (LSCS) (41.67\%), hypothyroidism (12.5\%), gestational diabetes mellitus $(20.83 \%)$ and gestational hypertension $(20.83 \%)$ with high BMI group compared to normal. Increased rate of anemia was observed with underweight group (56.25\%). The rate of neonatal intensive care unit (NICU) admission was more $(37.5 \%)$ in underweight group compared to normal $(8.34 \%)$. Conclusion: High BMI is associated with increased incidence of hypothyroidism, gestational diabetes mellitus, gestational hypertension, instrumental delivery and caesarean delivery. There is a significant association of underweight BMI with anemia and low birth weight.
\end{abstract}

Excessive weight is a major health problem in all affluent societies. Obesity continues to rise in prevalence around the globe. The global epidemic of obesity continues to grow at an alarming rate, crossing boundaries of age, race and gender. Indeed, it is now so common that it is replacing the more traditional public healthcare concerns like under nutrition and infectious disease as one of the most significant contributors to ill health ${ }^{1}$. The prevalence of obesity is increasing in pregnancy ${ }^{2}$, and has prompted the American College of Obstetricians and Gynecologists (ACOG) to recommend that the body mass index (BMI) should be recorded for all women at the
Keywords: BMI, obesity, high BMI, underweight.

initial prenatal visit, and that information concerning the maternal and fetal risks of a very elevated BMI in pregnancy should be provided ${ }^{3}$. WHO in 2009 announced obesity in pregnancy as one of the important non communicable diseases that threaten maternal and child health ${ }^{4}$.

Maternal obesity has been associated with adverse perinatal outcomes. Obese pregnant women are at increased risk of gestational diabetes, preeclampsia, infection, operative vaginal delivery, and caesarean delivery $^{5-9}$. They are also at increased risk for wound infection and endomyometritis ${ }^{10}$. Their offspring are at

Received: $11^{\text {th }}$ May 2018. Accepted: $16^{\text {th }}$ September 2018.

Ramya S, Kumar A, Sharan S, Ramaiah R. A study of body mass index in pregnancy and its correlation with maternal and perinatal outcome. The New Indian Journal of OBGYN. 2019; 5(2): 120-5 
increased risk for birth defects, macrosomia, and morbidity associated with subsequent childhood obesity $9,11,12$. In developing country like India, they also face problem of malnutrition and complications related to underweight like anemia, premature rupture of membranes, low APGAR scores, low birth weight babies, preterm delivery and increased perinatal mortality ${ }^{13-15}$. National health goals stated that goal of healthy people 2000 was to reduce the prevalence of overweight people to 20 percent or less by the end of the 20th century. This goal was not achieved, but by 2000 , more than half of the population became overweight ${ }^{16}$. These emphasize the need for the present study. The purpose of this study is to correlate the BMI in pregnancy with maternal and perinatal outcome.

\section{Materials and Methods}

It was a prospective observational study conducted on 100 pregnant women attending antenatal outpatient at ESIC MC PGIMSR, Bengaluru from January 2015 to June 2016 who fulfill inclusion and exclusion criteria.

Inclusion criteria: 1) Age of 18 - 35 years, 2) Singleton pregnancy, 3) Spontaneous conception, 4) $1^{\text {st }}$ trimester visit for confirmation of pregnancy.

Exclusion criteria: 1) Women with multiple pregnancies, 2) Women with chronic diseases such as hypertension, diabetes, thyroid disorder and bronchial asthma, 3) Women with previous cesarean section, 4) Women with uterine and fetal congenital anomalies. Women were informed about the study and purpose of study in detail. A detailed history regarding name, age, and obstetric score were taken. Estimated gestational age were calculated based on the last menstrual period and $1^{\text {st }}$ trimester ultrasound studies. Baseline weight and height were recorded during the initial visit in the first trimester and the basal BMI was calculated using the formula weight in kilograms divided by height in meters square $\left[\mathrm{kg} / \mathrm{m}^{2}\right]$. The above women were placed in standard BMI categories and patients were followed up throughout the pregnancy and the obstetric and neonatal outcome variables were evaluated. Any abnormal observations or if the patient developed any complication at any time of the study it was documented. Management of the complication was implemented. Statistical analysis was done using SPSS version 17. Categorical variables were reported using number and percentages. $\mathrm{P}$ value $<0.05$ was considered statistically significant.

The BMI is a simple index of the weight-for-height and it was calculated by dividing a person's weight kilograms by square of their height in meters $\left[\mathrm{kg} / \mathrm{m}^{2}\right]$. The women were categorized into four groups according to their BMI as per WHO classification (Table 1).

Table 1: BMI (WHO Classification)

\begin{tabular}{ll}
\hline Groups & BMI \\
\hline Underweight (group 1) & less than or equal to $18.5 \mathrm{~kg} / \mathrm{m}^{2}$ \\
Normal (group 2) & $>18.5-24.9 \mathrm{~kg} / \mathrm{m}^{2}$ \\
Overweight (group 3) & $25-29.9 \mathrm{~kg} / \mathrm{m}^{2}$ \\
Obese (group 4) & $30-34.9 \mathrm{~kg} / \mathrm{m}^{2}$ \\
\hline
\end{tabular}

\section{Results}

In this study we observed normal BMI: $36 \%(\mathrm{n}=36)$, underweight : $16 \%(\mathrm{n}=16)$, overweight : $38 \%(\mathrm{n}=38)$ and
Table 2: Distribution according to age and parity

\begin{tabular}{lllllll}
\hline Variables & $\begin{array}{l}\text { Under weight } \\
\text { No }(\%)\end{array}$ & $\begin{array}{l}\text { Normal } \\
\mathbf{N}(\%)\end{array}$ & $\begin{array}{l}\text { Overweight } \\
\mathbf{N}(\%)\end{array}$ & $\begin{array}{l}\text { Obese } \\
\mathbf{N}(\%)\end{array}$ & $\begin{array}{l}\text { Total } \\
\mathbf{N}(\%)\end{array}$ \\
\hline Age & $18-22$ & $3(18.75 \%)$ & $7(19.44 \%)$ & $9(23.68 \%)$ & $2(20 \%)$ & 21 \\
in & $23-29$ & $9(56.25 \%)$ & $26(72.22 \%)$ & $25(65.78 \%)$ & $6(60 \%)$ & 66 \\
years & $30-35$ & $4(25 \%)$ & $3(8.33 \%)$ & $4(10.52 \%)$ & $2(20 \%)$ & 13 \\
& Total & 16 & 36 & 38 & 10 & $100(100 \%)$ \\
\hline Parity & Primi & $6(37.5 \%)$ & $27(75 \%)$ & $28(73.68 \%)$ & $7(70 \%)$ & 68 \\
& 1 & $8(50 \%)$ & $6(16.66 \%)$ & $7(18.42 \%)$ & $2(20 \%)$ & 23 \\
& 2 & $2(12.5 \%)$ & $3(8.34 \%)$ & $3(7.89 \%)$ & $1(10 \%)$ & 9 \\
& Total & 16 & 36 & 38 & 10 & $100(100 \%)$ \\
\hline
\end{tabular}

obese BMI: $10 \%(\mathrm{n}=10)$. Majority of study population $66 \%(\mathrm{n}=66)$ were in the age group between $23-29$ years (table 2). Most of women $68 \%(\mathrm{n}=68)$ in study were primigravida (table 2). Among 36 women with normal BMI, 2.77\% ( $\mathrm{n}=1)$ had hypothyroidism, out of 38 women with overweight $7.8 \%(\mathrm{n}=3)$ had hypothyroidism, out of 10 women with obese BMI $30 \% \quad(n=3)$ had hypothyroidism (table 3). The overall incidence of hypothyroid in our study was $7 \%$. Increased rate of hypothyroidism was seen in obese $30 \%(\mathrm{n}=3)$ and overweight $7.8 \%(\mathrm{n}=3)$ compared to normal $2.77 \%(\mathrm{n}=1)$. 
Table 3: Maternal outcome with each BMI category

\begin{tabular}{lllll}
\hline Variables & $\begin{array}{l}\text { Hypothyroid } \\
\mathbf{N}(\%)\end{array}$ & $\begin{array}{l}\text { GDM } \\
\mathbf{N ~ ( \% )}\end{array}$ & $\begin{array}{l}\text { GHTN } \\
\mathbf{N ~ ( \% )}\end{array}$ & $\begin{array}{l}\text { Anemia } \\
\mathbf{N}(\%)\end{array}$ \\
\hline Under weight & $0(0 \%)$ & $0(0 \%)$ & $0(0 \%)$ & $9(56.25 \%)$ \\
Normal & $1(2.77 \%)$ & $3(8.34 \%)$ & $3(8.34 \%)$ & $10(27.77 \%)$ \\
Over weight & $3(7.89 \%)$ & $7(18.42 \%)$ & $7(18.42 \%)$ & $6(15.78 \%)$ \\
Obese & $3(30 \%)$ & $3(30 \%)$ & $3(30 \%)$ & $1(10 \%)$ \\
\hline
\end{tabular}

out of 38 women with overweight $18.42 \%$ $(n=7)$ had GHTN, out of 10 women with obese BMI 30\% $(n=3)$ had GHTN (table 3). Thus the overall incidence of gestational hypertension in present study was $13 \%$ and increased rate of GHTN in obese $30 \%(n=3)$, overweight $18.42 \% \quad(n=7)$ compared to

$P$ value of 0.015 signifying that in obese and overweight groups there was statistically significant increase in incidence of hypothyroidism.

Similarly, among 36 women with normal BMI, 8.34\% $(n=3)$ had gestational diabetes mellitus (GDM), out of 38

Table 4: Mode of delivery with each BMI category

\begin{tabular}{lllll}
\hline Mode of delivery & VD & LSCS & INS & Total \\
\hline Under weight & $14(87.5 \%)$ & $2(12.5 \%)$ & - & 16 \\
Normal & $29(80.55 \%)$ & $6(16.66 \%)$ & $1(2.77 \%)$ & 36 \\
Over weight & $22(57.89 \%)$ & $14(36.84 \%)$ & $2(5.26 \%)$ & 38 \\
Obese & $1(10 \%)$ & $6(60 \%)$ & $3(30 \%)$ & 10 \\
Total & 66 & 28 & 6 & 100 \\
\hline VD= Vaginal Delivery, INS= Instrumental & &
\end{tabular}

women with overweight $18.42 \%(\mathrm{n}=7)$ had GDM and out contribute $87.5 \%(\mathrm{n}=14)$, normal group were $80.55 \%$ $(\mathrm{n}=29)$ and overweight were $57.89 \%(\mathrm{n}-22)$. Among $28 \%$ of 10 women with obese BMI $30 \%(n=3)$ had GDM

Table 5: Neonatal outcome

\begin{tabular}{lllllll}
\hline Variables & & $\begin{array}{l}\text { Underweight } \\
\mathbf{N}(\%)\end{array}$ & $\begin{array}{l}\text { Normal } \\
\mathbf{N}(\mathbf{\%})\end{array}$ & $\begin{array}{l}\text { Overweight } \\
\mathbf{N}(\mathbf{\%})\end{array}$ & $\begin{array}{l}\text { Obese } \\
\mathbf{N}(\mathbf{\%})\end{array}$ & $\begin{array}{l}\text { Total } \\
\mathbf{N}\end{array}$ \\
\hline Birth & $<2.5$ & $13(81.25 \%)$ & $11(30.55 \%)$ & $6(15.78 \%)$ & - & 30 \\
weight in & $2.6-3.0$ & $3(18.75 \%)$ & $19(52.77 \%)$ & $15(39.47 \%)$ & $3(30 \%)$ & 40 \\
Kg & $3.1-3.5$ & - & $5(13.88 \%)$ & $14(36.84 \%)$ & $4(40 \%)$ & 23 \\
& $\geq 3.6$ & - & $1(2.77 \%)$ & $3(7.89 \%)$ & $3(30 \%)$ & 7 \\
& Total & 16 & 36 & 38 & 10 & 100 \\
\hline APGAR & $5-7$ & $12(75 \%)$ & $1(2.77 \%)$ & $2(5.26 \%)$ & $2(20 \%)$ & 17 \\
Score at 5 & $\geq 8$ & $4(25 \%)$ & $35(97.22 \%)$ & $36(94.73 \%)$ & $8(80 \%)$ & 83 \\
minute & Total & 16 & 36 & 38 & 10 & 100 \\
\hline NICU & None & $10(62.5 \%)$ & $33(91.66 \%)$ & $37(97.36 \%)$ & $10(100 \%)$ & 90 \\
admission & Yes & $6(37.5 \%)$ & $3(8.34 \%)$ & $1(2.63 \%)$ & - & 10 \\
& Total & 16 & 36 & 38 & 10 & 100 \\
\hline
\end{tabular}

of women with LSCS underweight group were $12.5 \%(\mathrm{n}=2)$, normal group were $16.66 \% \quad(\mathrm{n}=6)$ and overweight were $36.84 \%$ $(\mathrm{n}=14)$ (table 4). Among 6\% of women with instrumental delivery with normal BMI were $\quad 2.77 \% \quad(\mathrm{n}=1)$, overweight were $5.26 \%$ $(\mathrm{n}=2)$, obese were $30 \%$ $(\mathrm{n}=3)$. Thus, significant increase in instrumental delivery as BMI increases (P-Value: 0.013) was observed.

(table 3). The overall incidence of GDM in present study was $13 \%$. Increased rate of GDM was seen in obese $30 \%$ $(\mathrm{n}=3)$, overweight $18.42 \%(\mathrm{n}=7)$ compared to normal 8.34\% (n=3) (P-Value: 0.084). So, statistically significant increase in incidence of GDM was observed in high BMI groups.

In case of blood pressure, 36 women with normal BMI, $8.34 \%(n=3)$ had gestational hypertension (GHTN),
Increased rate of LSCS was seen in obese group $60 \%$ $(\mathrm{n}=6)$ and overweight group $36.84 \%(\mathrm{n}=14)(\mathrm{P}$ Value $0.013)$. Increased rate of vaginal delivery in underweight group $87.5 \%(\mathrm{n}=14)$ (P value 0.013). So, significant linear trend in the decrease in normal delivery as BMI increases was observed. In present study, majority of babies birth weight $40 \%(\mathrm{n}=40)$ were in between 2.6 to $3 \mathrm{~kg}$. Mean weight of babies in the study was $2.80 \mathrm{Kg}$ (table 5). Study 
also shows that majority of underweight women were significantly associated with low birth weight, as BMI increases birth weight increases.

In case of APGAR score, $17 \%(n=17)$ score between $5-7,83 \%(\mathrm{n}=83)$ score $>8$, average APGAR SCORE at 5 MINUTE was 8.43 (table 5). In this study, the NICU admission was $37.50 \%(\mathrm{n}=6)$ in underweight, $8.34 \%$ $(\mathrm{n}=3)$ in normal and in high BMI $2.63 \%(\mathrm{n}=1)$ with $\mathrm{P}$ value of 0.0002 . So, there was statistically significant increase in NICU admission with low BMI.

\section{Discussion}

In present study, 100 singleton pregnant women attending antenatal OPD at ESIC MC PGIMSR Bengaluru were included who met the inclusion and exclusion criteria. They were divided into 4 BMI groups, out of 100 women, $16 \%(\mathrm{n}=16)$ were in underweight group with BMI $<18.5 \mathrm{~kg} / \mathrm{m}^{2}, 36 \%(\mathrm{n}=36)$ were in normal group with BMI $18.5-24.9 \mathrm{~kg} / \mathrm{m}^{2}$. Overweight group were $38 \%(\mathrm{n}=38)$ with BMI $25-29.9 \mathrm{~kg} / \mathrm{m}^{2}$ and obese were $10 \%(\mathrm{n}=10)$ with BMI $>30 \mathrm{~kg} / \mathrm{m}^{2}$. Anjana Sharma ${ }^{17}$ et al in their study found that $14.79 \%$ were in underweight and $51.78 \%$ belonged to the normal weight category, while $21.04 \%$, $10.71 \%$ women were from the overweight, obese categories respectively. Yazdani ${ }^{18}$ et al found that $12.8 \%$ were underweight, $41.2 \%$ were normal, $35.6 \%$ were overweight and $9.8 \%$ were obese.

In the present study hypothyroid was found in $7 \%$ $(\mathrm{n}=13)$, which correlates result of $6.5 \%$ in $\mathrm{Sahu}^{19}$ et al, $7.4 \%$ in Taghavi $^{20}$ et al and 9\% in Sapana et al ${ }^{21}$. Present study shows statistically significant increase incidence of hypothyroidism $(\mathrm{P}=0.015)$ as BMI increases. Boas Forman $^{22}$ et al and $\mathrm{Mbah}^{23}$ et al also reported higher incidence of hypothyroidism with high BMI. In present study GDM was found in $13 \%(n=13)$ which correlates with $16.5 \%$ of Seshiah $\mathrm{V}^{24}$ et al. Study done in $\mathrm{TN}^{25}$ revealed that $17.8 \%$ GDM were in urban, $13.8 \%$ were in semi urban, $9.9 \%$ were in rural areas. Kumari ${ }^{26}$ et al comparing obese and non obese found that GDM incidence was $24.5 \%$ in obese. Rajesh Rajput $^{27}$ et al found that $22 \%$ of GDM were in obese. In the present study $30 \%$ of obese patients had GDM. So, there was statistically increased incidence in GDM in high BMI.

In present study GHTN was found in $13 \%(n=13)$, among them $30 \%(n=3)$ were in obese, $18.42 \%(n=7)$ were in overweight and $8.34 \%(\mathrm{n}=3)$ were in normal BMI group. So there was statistically significant increase in incidence of GHTN with rising BMI with $\mathrm{P}$ value of 0.084 . Kumari $^{27}$ et al found $28.8 \%$ of GHTN in obese with $2.9 \%$ in the non obese with a significant correlation of high BMI with GHTN.

In this study anemia was found in $26 \%(\mathrm{n}=26)$. Prevalence of anemia in developing countries is $33-75 \%$ as per WHO. Our study correlates with Emmanuel ${ }^{28}$ et al $(21.7 \%)$. In present study $56.25 \% \quad(n=9)$ were in underweight, $15.78 \%(\mathrm{n}=6)$ were in overweight and $10 \%$ $(n=1)$ in obese women had anemia, shows statistically increase in incidence of anemia as BMI decreases with $\mathrm{P}$ value of 0.011. Qin $\mathrm{Yu}^{29}$ et al in their study found inverse association between overweight, obese and anemia in Chinese women.

In this study $36.84 \%(n=14)$ of overweight, $60 \%(n=6)$ of obese and $16.66 \%(n=6)$ of normal BMI women were undergone LSCS. So there was statistically significant increase in LSCS as BMI increases with $p$ value of 0.0131. Poobalan ${ }^{30}$ et al in their study found that incidence of LSCS was higher in overweight or obese women than with normal BMI. Jang $\mathrm{DG}^{31}$ et al in his study revealed similar type of findings. In present study, there was significant increased in instrumental delivery in high BMI cases. Johnson ${ }^{32}$ et al also stated that obesity causes increased incidence of operative vaginal deliveries.

In present study $30 \%$ of babies had weight $<2.5 \mathrm{~kg}$, $40 \%$ of babies with weight $2.6-3 \mathrm{~kg}, 23 \%$ of babies with weight $3.1-3.5 \mathrm{~kg}$ and $7 \%$ of with weight $>3.6 \mathrm{~kg}$. In our study lower BMI was significantly associated with low birth weight and as BMI increases there was increase in birth weight of baby, correlating with studies of Frederick $^{33}$ et al.

The average APGAR SCORE at 5 min was 8.44. Present study failed to establish a significant correlation between BMI and APGAR score. This corresponds with Tatiana Papazian ${ }^{34}$ et al who found similar findings that pre-pregnancy BMI was not predictor of poor APGAR.

In this study $37.5 \%(n=6), 8.34 \%(n=3)$ and $2.63 \%$ $(\mathrm{n}=1)$ were in underweight, normal and overweight group baby required NICU admission respectively which shows significant increase in NICU admission as BMI decrease and it correlates with the study of Kalk $\mathrm{P}^{35}$ et al. 


\section{Conclusion}

The study of maternal BMI shows strong associations with pregnancy complications and outcomes. High BMI is associated with increased incidence of hypothyroidism, gestational diabetes mellitus, gestational hypertension, instrumental delivery and caesarean delivery. There is a significant association of underweight BMI with anemia and low birth weight.

\section{Conflict of interest: None. Disclaimer: Nil.}

\section{References}

1.WHO. Obesity: preventing and managing the global epidemic. WHO Tech Rep Ser. 2000; 894: 1-253.

2.Alexandara P, Vassilios B, Alexandara V, George K, Vassiliki L, Chryssa B. Population based trends of pregnancy outcome in obese mothers: what has changed over 15 years . Obesity. 2011; 19:1861-5.

3.American College of Obstetricians and Gynecologists. Obesity in pregnancy. Obstet Gynecol. 2005; 106(3): 671-5.

4.WHO. Discussion paper: Non communicable diseases, poverty and the development agenda (July 2009) ECOSOC high level segment; 2009. http:// www.who.

int $/ \mathrm{nmh} /$ publications / discussion_paper_ncd_en.pdf

5.Rosenberg TJ, Garbers S, Chavkin W, Chiasson MA. Prepregnancy weight and adverse perinatal outcomes in an ethnically diverse population. Obstet Gynecol. 2003; 102 (5 Pt 1): 1022-7.

6.Wall PD, Deucy EE, Glantz JC, Pressman EK. Vertical skin incisions and wound complications in the obese parturient. Obstet Gynecol. 2003; 102(5 pt 1): 952-6.

7.Jensen DM, Damm P, Sorensen B, Molsted-Pedersen L, Westergaard JG, Ovesen P. Pregnancy outcome and prepregnancy body mass index in 2459 glucose-tolerant Danish women. Am J Obstet Gynecol. 2003; 189(1): 239-44.

8.O'Brien TE, Ray JG, Chan WS. Maternal body mass index and the risk of preeclampsia: a systematic overview. Epidemiology. 2003;14(3): 368-74.

9.Castro LC, Avina RL. Maternal obesity and pregnancy outcomes. Curr Opin Obstet Gynecol. 2002; 14(6): 601-6.

10.Myles TD, Gooch J, Santolaya J. Obesity as an independent risk factor for infectious morbidity in patients who undergo cesarean delivery. Obstet Gynecol. 2002; 100(5 Pt 1): 959-64.
11.Watkins ML, Rasmussen SA, Honein MA, Botto LD, Moore CA. Maternal obesity and risk for birth defects. Pediatrics. 2003; 111(5 Pt 1): 1152-8.

12.Cedergren MI, Kallen BA. Maternal obesity and infant heart defects. Obes Res. 2003; 11: 1065-71.

13.Wolfe HM, Zador IE, Gross TL, Martier SS, Sokol RJ. Clinical utility of maternal body mass index in pregnancy. Am J Obstet Gynacol. 1991. 164(5 Pt 1): 1306-10.

14.Naevy RL. Maternal body weight and pregnancy outcome. Am J Clin Nutr. 52(2): 273-9.

15.van der Spuy ZM, Steer PJ, McCusker M, Steele SJ, Jacobs HS. Outcome of pregnancy in underweight women after spontaneous and induced ovlation. British Med J (Clin Res Ed). 1988; 296(6627): 962-5.

16.Ehrenberg HM, Dierker L, Milluzzi C, Mercer BM. Prevalence of maternal obesity in an urban center. Am J obstetrics and gynecology. 2002; 187(5): 1189-93.

17.Verma A, Sharmali L. A study of body mass index in pregnancy and its correlation with maternal and perinatal outcome. Journal of clinical and Diagnostics research. 2017; 4(4): 359-63.

18. Yazdani S, Yosofniyapasha Y, Nasab BH, Mojaveri MH, Bouzari Z. Effect of maternal body mass index on pregnancy outcome and newborn weight. BMC Res Notes. 2012; 5: 34.

19.Sahu MT, Das V, Mittal S, Agarwal A, Sahu M. Overt and subclinical thyroid dysfunction among Indian pregnant women and its effect on maternal and fetal outcome. Archives of Gynecology and Obstetrics. 2010; 281(2): 21520 .

20.Taghavi M, Saghafi N, Shirin S. Outcome of Thyroid Dysfunction in Pregnancy in Mashhad, Iran. Int J Endocrinol Metab. 2009; 2: 82-5.

21.Shah SC, Shah CR. Thyroid disorders in pregnancy - a comparative study. International journal of fundamental and applied life sciences. 2015; 5(1): 7-14.

22.Boas M, Forman J, Juul A, Feldt-Rasmussen U, Skakkebaek N, Histeled L, et al. Narrow intra-individual variation of thyroid function in pregnancy based on longitudinal study on 132 women. Eur J Endocrinol. 2009; 161(6): 903-10.

23.Mbah A, Ejim E, Onodugo O, Ezugwu F, Eze M, Nkwo $\mathrm{P}$, et al. Two logistic models for the prediction of hypothyroidism in pregnancy. BMC Res Notes. 2011; 4: 205.

24.Seshiah V, Balaji V, Balaji MS, Sanjeevi CB, Green A. Gestational diabetes mellitus in India . J Assoc Physicians India. 2004; 52:707-11. 
The New Indian Journal of OBGYN. 2019 (January-June); 5(2)

25.Seshiah V, Balaji V, Balaji MS, Paneerselvam A, Arthi T, Thamizharsi M, et al. Prevalence of Gestational diabetes mellitus in South India - a community based study. J Assoc Physicians India. 2008; 56: 328-33.

26.Kumari AS. Pregnacy outcome in women with morbid obesity. Int J Gynecol Obstet. 2001;73(2):101-7.

27.Rajput R, Goel V, Nanda S, Rajput M, Seth S. Prevalence of thyroid dysfunction among women during the first trimester of pregnancy at a tertiary care hospital in Haryana. Ind J Endocrinol Metab. 2015; 19(3): 416 - 19.

28.Ugwuja EI, Ogbonnaya LU, Obuna AJ, Awelegbe F, UroChukwu H. Anaemia in Relation to Body Mass Index and Sociodemographic Characteristics. Journal of Clinical and Diagnostic Research. 2015; 9(1): LC04-LC07

29.Qin Y, Melse-Boonstra A, Pan X, Yuan B, Dai Y, Zhao J, et al. Anemia in relation to body mass index and waist circumference among chinese women. Nutrition Journal. 2013, 12:10

30.Poobalan AS, Aucott LS, Gurung T, Miller RS, Smith WC, Bhattacharya S. Obesity as an independent risk factor for elective and emergency caesarean delivery in nulliparous women. Obes Rev. 2009;10(1): 28-35.

31.Jang DG, Jo YS, Lee GS. Effect of pre-pregnancy body mass index and weight gain during pregnancy on the risk of emergency caesarean section in nullipara. Arch Gynecol Obstet. 2011 Dec; 284(6): 1389-97.

32.Johnson JW, Longmate JA, Frentzen B. Excessive maternal weight and pregnancy outcome. Am J Obstet Gynecol.1992; 167: 353-70.

33.Frederick IO, Williams MA, Sales AE, Martin DP, Killien M. Pre pregnancy Body Mass Index, Geatational weight gain and other maternal Characteristics in relation to infant birth weight. Matern Child Health J. 2008 Sep; 12(5): 557-67.

34.Papazian T, Tayeh GA, Sibai D, Hout H, Melki I, Khabbaz LR. Impact of maternal body mass index and gestational weight gain on neonatal outcomes among healthy Middle-Eastern females. PLoS One. 2017; 12(7): e0181255

35.Kalk P, Guthmann F, Krause K, Relle K, Godes M, Gossing $\mathrm{G}$, et al. Impact of maternal body mass index on neonatal outcome. Eur J Med Res. 2009 May 14;14(5):21622 .

Ramya S $^{\mathbf{1}}$, Ashok Kumar ${ }^{2}$, Shweta Sharan $^{\mathbf{3}}$, Renuka
Ramaiah $^{4}$
1,2,3,4 Department of Obstetrics and Gynaecology,
ESICMC PGIMSR, Rajajinagar, Bengaluru, Karnataka,
India

